\title{
RÉPLICA NÃO CONCLUSIVA ${ }^{1}$
}

Luca Diotallevi ${ }^{2}$

Agradeço a esta revista pela honra que me concedeu e pela oportunidade que me ofereceu. Agradeço aos colegas que tomaram em consideração o meu texto. Agradeço-os pela atenção, na esperança de que o seu esforço seja pelo menos em parte recompensado. Agradeço-os também e, sobretudo, pelas críticas que formularam. Dada a sua capacidade de estimular a pesquisa, elas constituem o melhor prêmio que o diálogo científico pode oferecer.

$\mathrm{Na}$ réplica solicitada, não me debruçarei sobre os pontos de consenso. Eu gostaria, pelo contrário, de me dedicar às críticas verdadeiras, em vários casos, formuladas por diversos autores. Penso poder coletá-las em seis.

Peço desculpas antecipadamente por qualquer mal-entendido ou excesso de simplificação. Também, por isso, a resposta que segue deve ser entendida não como um encerramento do confronto, mas como um relançamento que o mantém aberto e que, caso consiga, procura, por sua vez, fazê-lo progredir.

$\mathrm{Na}$ resposta, eu não gostaria de insistir nas referências à literatura. Os textos que precedem, no seu conjunto, colocam-se em um lugar ideal do debate sociológico dentro do qual se insere esta réplica. As coordenadas deste espaço já foram esclarecidas. Além disso, e para não sobrecarregar esta segunda intervenção, permito-me reenviar a um trabalho meu que está para ser publicado: L'ordine imperfetto: Modernizzazione, Stato, secolarizzazione (Rubbettino, 2014) (A ordem imperfeita. Modernização, Estado, secularização), no qual poderão facilmente encontrar ainda mais detalhadas as referências à literatura científica.

\footnotetext{
1 Traduzido por Claude Petrognani.

2 Professor da Universidade de Roma TRE. Contato: luca.diotallevi@uniroma3.it
} 


\section{POUCA ATENÇÃO À EXPERIÊNCIA RELIGIOSA SUBJETIVA}

Tanto Portier quanto Cipriani, também explicitamente, indicam no meu texto pouca atenção à dimensão subjetiva da experiência religiosa. Como todos sabemos, esta crítica exprime uma tensão clássica e crucial da sociologia (e não somente da "sociologia da religião"). Acredito que os dois colegas percebem muito bem a minha orientação. Essa exprime uma particular ideia da sociologia e das suas competências. Efetivamente, pelo que pode valer, não estou convencido de nenhuma das propostas sociológicas que pretendem tratar também (e algumas até mesmo: apenas) da experiência subjetiva da religião ou de qualquer outro tipo. Acredito, antes, que a sociologia tenha encontrado um lugar entre as ciências somente a partir do momento em que, e possa mantê-lo somente na medida em que, ocupa-se da relativa - ou seja, nem absoluta nem nula - autonomia dos fenômenos sociais acerca das realidades que têm por cenário a consciência pessoal ou, a um nível ainda mais elementar, a dimensão exclusivamente psico-físico-químico-biológica do corpo humano. Portanto, é absolutamente correto sustentar que o meu texto é mais uma expressão de uma sociologia que se ocupa de comunicações (e entre estas também das açôes), de instituições, de organizações e de semânticas enquanto realidades (sistemas, do ponto de vista particular que eu tento seguir) sociais. Esta posição não implica de modo algum que não existam fenômenos atribuíveis à subjetividade, nem que esta seja menos importante da realidade social ou determinada por esta, nem que esta última não possa ser fortemente condicionada por aquela, nem, enfim, que não possa ser também objeto de análise científica. Simplesmente, esta é a posição epistemológica implícita, a sociologia produz teorias e conhecimento mais úteis quando assume não ser competente diretamente pela experiência subjetiva e quando - entre outras coisas - limita-se a estudar apenas as perturbações e as influências que produz sobre o social. 
Talvez neste ponto possa ser útil acrescentar duas breves notas:

a. Por si só o critério apenas enunciado não é questionado quando a sociologia emprega conceitos como o de "religiosidade" ou de "demanda religiosa", ou outros semelhantes. Mesmo nesse caso, de fato, trata-se ainda de comunicações (e eventuais ações), de instituições ou de semânticas e acoplamentos estruturais. Este é muito evidente - por exemplo - quando analisam-se os indicadores empregados pela literatura baseada no uso do modelo multidimensional da análise da religiosidade (de Glock e Stark em diante) ou naquela que estuda os fenômenos da demanda religiosa (Iannaccone) ou do consumo religioso (B. S. Turner).

b. Na perspectiva teórica elaborada por Niklas Luhmann, a que o texto em questão tenta utilizar, o ponto apenas mencionado assume uma forma muito precisa e muito radical. As pessoas, de um lado, e as realidades sociais, de outro, possuem pelo menos um grau comum de realidade, entendendo-se que não se dariam os segundos sem os primeiros; possuem uma estrutura significativamente heterogênea e reciprocamente irredutível, podem reciprocamente influenciar-se, perturbar-se, desenvolver acoplamentos estruturais (ou, de acordo com uma categoria um pouco mais simples, interpenetrar-se). $\mathrm{O}$ fato que sejam - brutalmente - "dois tipos de coisas diferentes" não significa que não tenham relações. O fato de haver relações, porém, não justifica a existência de uma única disciplina científica competente para ambos. Mesmo nesse caso, parece-me que Luhmann se coloca no rastro de muitos clássicos, Weber e Simmel, primeiramente, e, por exemplo, da distinção entre social e pessoal que este último mantém quando sustenta que diferenciação social e individuação, apesar de não ser a mesma coisa, procedem juntas. De outra parte, parece-me que Luhmann, muito mais que Habermas, dá conta e respeita a irredutibilidade do pessoal ao social, diria o excedente, quase a transcendência do pessoal sobre o 
social. O racionalismo de Habermas considera o pessoal mas para lhe ditar regras morais e para assimilá-lo. Talvez devido a um excesso de kantismo de minha parte, mas o interesse de Habermas a prescrever o que é necessário para o meu bem e para o bem da sociedade causa-me suspeita. Ainda mais quando isto ocorre em nome da razão e impondo aos indivíduos que pretendem tornar-se cidadãos de pleno direito estranhas obrigações de tradução ou, pelo menos, de traduzibilidade das suas razões na sua razão (Sweetman).

\section{DÉFICIT DE HISTORICIDADE}

Uma parte dos comentadores sublinhou um significativo déficit de historicidade: pouca atenção à variedade que os fenômenos estudados assumem, seja em termos sincrônicos ou em termos diacrônicos.

A respeito disso, penso poder propor três argumentos:

a. O primeiro e o mais importante é que verdadeiramente poucos sociólogos (incluídos os "clássicos") podem se orgulhar de uma utilização vasta das suas teorias, tanto de parte da sociologia histórica (Gorski) quanto da pesquisa historiográfica, no sentido próprio (pode-se pensar, por exemplo, em muitos expoentes da escola do Konfessionalisierungparadigm). Naturalmente, é muito provável que a minha utilização das teorias de Luhmann não tenha as qualidades dos casos apenas citados, mas, justamente, por esta razão, o eventual déficit de historicidade da análise que propus tem pouco a ver com a contribuição do sociólogo alemão.

b. Em segundo lugar, conviria controlar o que resta das críticas de a-historicidade uma vez isolado o peso de um fator diferente. $\mathrm{O}$ texto que propus reflete, pelo menos em parte, reconstruçóes históricas certamente não minoritárias na literatura sociológica em geral, mas, certamente, minoritárias entre as reconstruções das quais se vale a sociologia e em particular a sociologia da religião de língua latina (francês, português, espanhol, italiano). Com isso, não se quer abso- 
lutamente sustentar que a reconstrução histórica aqui adotada seja aquela "verdadeira" enquanto que a prevalecente na porção da sociologia apenas indicada seja a "falsa". Para chegar a uma conclusão semelhante, dever-se-ia entrar no mérito. Em todos os casos, acho extremamente útil poder discutir esta crítica. Fazendo isso, acaba-se, de fato, por tocar num tema ainda mais importante. Ou seja: de qual historiografia da modernidade depende a sociologia (e, mais uma vez, não apenas a sociologia da religião)? Muito poucos de nós nos colocamos uma questão deste tipo. Pensemos somente o quanto ela pode ser relevante quando enfrentamos problemas estruturalmente diacrônicos como o da secularização. Em casos como este, não é absolutamente a mesma coisa assumir a narrativa de Berman ou Grossi ao invés daquela de Böckenförde ou P. Prodi, aquela racionalista idealista em lugar de outras. No fundo, o que estamos lidando não é outra coisa se não a enésima variante de um interrogativo crucial e muitas vezes removido na sociologia (da religião) de língua latina: quanto esta sociologia depende ainda da ideologia da laicidade e da III República Francesa? Por exemplo, podemos bem dizer que o processo de formação do estado na França se ressente do confronto com a realidade muito importante da Igreja e do catolicismo franceses. Mas, por que assumir como certo que a única forma de modernização política seja aquela que conduz o poder político à sua forma absoluta, à soberania, à subordinação de qualquer outra instituição social? $\mathrm{O}$ evento da modernização política mostra-nos, pelo contrário, também outros percursos e a diversidade entre estes e aquele francês não pode ser nem explicada nem arquivada recorrendo à presença de um competidor católico ou a diversos graus de homogeneidade/pluralismos religiosos (a respeito disso, ver, entre outros, Rokkan, Gorski etc.). Por um lado, podemos encontrar modelos de evolução política que apontam para uma diferenciação por especialização e não por absolutismo. Por outro lado, podemos encontrar firmemente raízes luteranas (a teoria dos "dois Reinos") para a pretensão de um domínio político sem resíduos sobre a ordem social. Ou ainda, e mais profundamente, podemos representar a modernização como 
afirmação progressiva do Estado e da sua laicidade (ou seja, da sua religião política e da sua autossacralização), ou, ao contrário, podemos representar o processo de modernização como uma série de multiple modernities (Eisenstadt), ou, ainda, podemos representar a modernização como uma progressiva afirmação do primado da diferenciação da sociedade por funções e, portanto, o estado absoluto como movimento de reação, de deformação e de freio modernos da modernização (Germani, Luhmann etc.). Neste último caso, o "Estado" e a state society aparece não como protótipo mas como degeneração da modernidade. A discussão acerca da utilidade destas e de outras hipóteses deve ser deixada para o confronto, entre outras, das disciplinas históricas e das sociológicas, mas, no entanto, podemos dizer sem ferir ninguém que apenas na primeira hipótese surge a pretensão - avançada justamente só por esta hipótese - de ser a única e que esta mesma singular hipótese exclusiva desenvolve ainda o papel de não criticamente discutir o quadro de orientação na maior parte da sociologia em línguas latinas. É, então, dentro desta sociologia que a opção laica, agora quase sempre na defensiva, adota a mesma estratégia defensiva que evoca uma não diversa definida e justificada pluralidade de laicidade e aquela, complementar, de definir "laicos" também os modelos de liberdade religiosa. A hipótese laica procura, assim, sobreviver à falsificação (ou seja, o desmascaramento de uma insustentável pretensão de universalidade), salvando a sua própria marca de "laicidade/laico", mais uma vez empiricamente e até mesmo filologicamente um injustificável respiro de "espécie", e não somente de "gênero". Ou, ainda, algo semelhante acontece quando ao lado da oportuna recordação das raízes religiosas (de matriz cristã) da ideia de absolutismo político, realizado por C. Schmitt (Pace), não se recorda a matriz também religiosa (e também cristã) do seu oposto e a deslegitimação das pretensões operadas por E. Peterson.

Termino este ponto assinalando um possível tema de pesquisa. Por que os sociólogos (da religião) acolhem acriticamente uma representação do magistério do Concilio Ecumênico Vaticano II como momento de reconciliação entre o catolicismo oficial e a laicidade, enquanto que com 
a declaração do mesmo Concilio sobre a liberdade religiosa, Dignitatis humanae, nos encontramos na presença da mais radical condenação da laicidade e da mais radical opção para os princípios da solução característica do regime de religious freedom? Uma solução que prevê um regime de separação entre poderes políticos e poderes religiosos em todos os aspectos alternativos daquela da laicidade.

c. Entre outros, Portier, Oro/Petrognani e Birman percebem, com razão, na minha opinião, a ligação entre o que consideram um defeito de historicidade e o esforço presente neste texto em adotar definiçóes, $\mathrm{o}$ quanto mais possíveis, precisas e formais. Parece-me que a parte importante do seu dissenso seja aquela considerada no ponto precedente b). Todavia, muitas vezes, é por trás de problemas de ordem metodológica como este que a consideração do ponto b) pode acabar se tornando assim invisível e, portanto, deixar de exercer o próprio estímulo positivo em relação ao pensamento e à pesquisa. Por isso que creio ser útil ensejar todos os esforços para jogar por terra esconderijos desse tipo.

O desejo de compreender cientificamente o contingente e, portanto, também o multiforme e o variável é algo a que não se pode renunciar. E, realmente, só Deus sabe quanto é contingente, multiforme e variável o social. Agora, dado que o conhecimento não é só do tipo científico, e que este - o conhecimento científico - é simplesmente diferente (nem melhor nem pior) em relação aos outros, trata-se de se manter nos seus próprios caracteres. Em suma: a principal das suas características é o interobjetivo controle dos seus acertos e das suas passagens lógicas. Se prescindirmos disso, simplesmente deixa-se de fazer ciência. A necessidade de definir conceitos antes de empregá-los e a transparência da estrutura lógica das teorias são ideais reguladores que podem ser satisfeitos/preenchidos em mais outras maneiras, mas das quais não se pode escapar.

As definiçôes, as teorias e as operações devem ser sempre discutidas. Elas possuem a forma própria para poderem ser facilmente controladas e discutidas. Portanto, podem ser, devem ser e de fato têm sido inúmeras 
vezes substituídas... Mas, na verdade, substituídas por outros conceitos, outras teorias e outros procedimentos operativos, que somente depois de definidos podem ser sempre arriscadamente e provisoriamente utilizados. Ao contrário, não tem nenhuma utilidade criticar uma teoria ou uma definição pela sua abstração e pela sua incapacidade de acompanhar a realidade em todas as suas nuances e suas mudanças. Se elas servem para o conhecimento científico, que é sempre artificial, limitado, finito, específico, é porque os seus instrumentos e seus métodos possuem estas características. Não importa o que nos tenha dado a sugestão ou como as ideias científicas nos chegaram à mente (Popper, Kuhn). O que importa - para começar um trabalho científico - é que lhe seja dado uma forma que permita um uso particular e uma particular forma de questionamento. $\mathrm{O}$ conhecimento científico não pode se emancipar do seu caráter altamente seletivo; só pode-se deixá-lo transparecer. Além de um certo limite, não é nem mesmo útil aumentar a complexidade das definiçóes, das operaçóes e das teorias, porque, dessa maneira, tornam-se rapidamente inutilizáveis.

Em suma, um conceito, um esquema, uma matriz para a classificação, um método ou uma teoria são feitas exatamente para serem criticadas, mas a crítica consiste não em chorar ou em estigmatizar a univocidade e o caráter abstrato, mas em propor outros conceitos, outros esquemas, outras matrizes, outros métodos e outras teorias mais úteis para resolver os mesmos problemas. Abstração e univocidade estão entre as características mais preciosas dos conceitos científicos, e devem ser elogiadas onde podem ser reencontradas. Caso contrário, o que resta é conversa fiada e não crítica.

A estas condições não escapa nem mesmo a análise histórica, a qual tendo a ver com eventos únicos e não com regularidade e formas (como a sociologia), e devendo empregar os instrumentos de diferentes disciplinas, aprecia ainda mais qualidades como a formalidade e a precisão. Graças a elas, e não à perfumaria e a oportunismos cognitivos, ela consegue aproximar, por aquele pouco ou muito que a ciência pode, a originalidade do singular e muitas vezes irrepetível evento.

Debates do NER, Porto Alegre, ANo I6, N. 27, P. I27-I4I, JAN./JUn. 2015 


\section{QUANTAS LAICIDADES?}

Numerosas críticas possuíam por objeto a noção de laicidade utilizada no texto. Até onde pude observar, pode ser acrescentada uma nota adicional:

i. Considerando que nos encontramos com dois construtos lógicos irredutíveis um ao outro - (a) privatização da religião, ordem social monárquica, civil law, religion civile e (b) não privatização da religião, ordem social poliárquica, common law, civil religion;

ii. Admitido (e não concedido) que (a) se mostra relativamente e comparativamente útil em identificar primeiramente o regime francês de separação entre poderes políticos e poderes religiosos e $(b)$ o regime britânico e estadunidense de separação entre poderes políticos e poderes religiosos mas também (com aceitação da Corte Constitucional italiana e da sua sentença 203/1989) aquele pelo qual opta a Constituição italiana em vigor;

iii. Reconhecida a variedade dos fundamentos assumidos por estes dois regimes no tempo e a multiplicidade das soluçôes que no tempo e no espaço a modernidade ofereceu ao problema da separação entre poderes políticos e poderes religiosos, acabamos por nos encontrar com pelo menos dois problemas bastante precisos:

- Dentro da variedade sincrônica e diacrônica a qual nos referimos em iii, há casos de regimes de separação entre poderes políticos e poderes religiosos que não possuem os citados quatro (em $i$ ) tipos de $(a)$ sem, por isso, ter aqueles de $(b)$ ? É abordando diretamente uma questão desse tipo que se pode apreciar ou contestar a utilidade do par de constructos lógicos em questão, dos quais é logicamente impossivel imaginar um híbrido (Giumbelli). Sem essa característica lógica, e talvez também sombreando os contornos e as condiçõos dos dois construtos, seria impossível dar-se conta se a realidade social e histórica - como muitas vezes ocorre - tem sido capaz de ir além das capacidades da nossa imaginação; 
- Estamos em condição de não nos prender na constatação de que tanto num como em outro caso, mas em termos muitos gerais, pode-se falar de "pluralismo ordenado" (Portier) ou de "panorama religioso heterogêneo do espaço público" (Pace) ou semelhantes? Utilizar o nosso esquema permite dar prosseguimento a perguntas como aquela recentemente feita por J. Casanova: "quem traça a separação entre política e religião?” Porque é evidente que uma coisa é ser política a traçar a linha de separação entre política e religião, e uma outra é se esta linha é o produto do conflito, sem vencedores nem árbitros entre política e religião (e, talvez, entre política, religião e direito). Em suma, recorrendo a um esquema como aquele proposto, sem excluir que outros esquemas possam funcionar como este, ou ainda melhor, é possível (para utilizar os termos de Portier) distinguir se a ordem para o pluralismo é dada exclusivamente pela via política, ou, então, não; se o espaço público religiosamente heterogêneo (para utilizar os termos de Oro/Petrognani) é definido somente pela política ou então não. Em suma: o pluralismo posto abaixo e dentro do primado da política não é a mesma coisa do que o pluralismo dentro do qual está como a religião e também a política e que esta última relativiza as reivindicações, não as sobrepondo nem as submetendo definitivamente nem às instâncias da religião nem a outras. Esta operação analítica é simplesmente impossível caso se siga Baubérot e se considerar o regime de religious freedom simplesmente como uma das "tantas laicidades do mundo".

Uma coisa é fazer sociologia para defender a laicidade, também ao custo de dispersar saber sociológico, outra coisa é tentar acumular saber sociológico aceitando contrastar as modas culturais (e os poderes) dominantes ou também apenas localmente dominantes. $\mathrm{O}$ texto de Roldán, por exemplo, pareceria mostrar uma certa utilidade do esquema proposto, uma vez aplicado ao caso argentino. 


\section{A PROPÓSITO DE DIFERENCIAÇÃO SOCIAL}

Críticas análogas, embora menos difusas e menos explícitas, dizem respeito à noção de diferenciação social em torno da qual, de fato, discorre o texto. Readaptado a este caso, poderia ser dito algo de muito semelhante ao que foi dito anteriormente a propósito de "laicidade".

Muito mais rapidamente, aqui gostaria apenas de reenviar a noção luhmanniana de modernização. Esta pode ser entendida como primado da diferenciação por funçôes da sociedade sobre as outras formas de diferenciação social (segmentação, centro/periferia, estratificação etc.). Primado não implica substituição. As outras formas de diferenciação social continuam a funcionar, mas simplesmente o fazem a partir de, ou seja, condicionadas pelo primado de um particular tipo de diferenciação social. A noção de diferenciação social em Luhmann é precisa, e muito diferente de outras, em particular daquela proposta por Parsons. Por outro lado, nem todas as formas de diferenciação social é diferenciação funcional da sociedade (Giumbelli). Isto significa que onde há não somente a diferenciação funcional da sociedade, mas o primado desta sobre outras formas de diferenciação social, este caso contingente e preciso obriga a analisar com atenção e no detalhe quanto os outros tipos de diferenciação social resultam não anulados, mas deformados a partir dele, e como, nestas circunstâncias específicas, desenvolvem a sua ação.

Acrescento duas notas. A compreensão da modernização elaborada por Luhmann consente (a) considerar os casos de positiva relação entre aquelas que Weber chamava de "esferas sociais": na forma da interpenetração ou naquela do acoplamento estrutural, por exemplo. Nessa direção é possível dar conta de como o primado da diferenciação funcional da sociedade não significa absolutamente redução, mas, pelo contrário, aumento das relações e, de como, no âmbito da noção de relação (Giumbelli), há ainda espaço para distinguir cooperação e conflito, perturbação e influência, e muito mais.

Debates do NER, Porto Alegre, Ano I6, N. 27, P. I27-I4I, JAN./Jun. 2015 
(b) Além disso, a teoria luhmanniana que estamos considerando ajuda a considerar distintamente o efeito deste processo em nível global, em nível regional e também em nível local, mas também as suas relações. Em particular, o caráter global do primado da diferenciação funcional da sociedade não exclui que permaneçam também significativas diferenças entre âmbitos regionais também contíguos nos quais se afirmam diferentes regimes de acoplamentos estruturais entre subsistemas, dando, assim, lugar a "configuraçôes" muito diferentes, segundo um esquema utilizado, entre outros, por P. F. Kjaer, com resultados importantes.

\section{CLASSIFICAR NÃO É EXPLICAR}

Classificar não é explicar; muito menos, prever. Portanto, não podemos deixar de concordar com a observação, explícita em Pace e implícita em outros comentários, de que o texto deixa em aberto a questão de como evoluem os modelos. O texto, de fato, concentra-se na crítica e na eventual revisão de um particular modelo de classificação (separatismo moderado vs. separatismo radical).

Qual pode ser a contribuição para a explicação do que é legítimo esperar de uma hipótese de classificação? Pelo menos duas, parece-me. Por um lado, uma classificação reenvia a uma teoria e, portanto, predispõe um elemento essencial dos procedimentos de previsão (tanto em relação a um período de tempo decorrido quanto a um período de tempo a chegar) e, depois, de controle das previsões. Admitido que a expressão seguinte tenha uma qualquer plausibilidade, com uma classificação "a-teórica” não seria possível conduzir alguma operação científica (que, obviamente, não exclui que esta - como qualquer outra ideia, ainda que vaga - possa ser causa remota de úteis inspirações, também do tipo científico). Por outro lado, e convém fazer referência direta ao caso tratado no texto que está sendo discutido, uma classificação pode ser útil também para enfatizar o caráter crucial de uma variável. No caso em questão, procura-se colocar em evidência o papel da relação direito/política (e, portanto, direito/lei) acerca da identificabilidade

Debates do NER, Porto Alegre, ANo I6, N. 27, P. I27-I4I, JAN./JUn. 2015 
de regimes diferentes de separação entre poderes políticos e poderes religiosos. (A semelhantes conclusões chegam também autores como Richardson). Agora, não há dúvidas de que a literatura sociológica, no que diz respeito às relações entre política e religião, só raramente leva em consideração tal variável, assim como trata como sinônimos "lei" e "direitos", talvez mesmo acriticamente, assumindo a lei como fonte do "direito". (Trata-se do enésimo exemplo da forte e persistente influência em uma parte tão grande desta disciplina da cultura da Terceira República francesa, do seu estatismo e do conseguinte "nacionalismo metodológico"). Uma hipótese de classificação como aquela avançada, segundo a qual a consubstancialidade de regimes jurídicos reciprocamente incomensuráveis ajuda a distinguir entre regime de laicidade e regime de liberdade religiosa, pode proporcionar uma boa ocasião à sociologia para discutir a utilidade de alterações na própria orientação prevalente.

\section{É SEMPRE MAIS URGENTE SEPARAR PODERES POLÍTICOS E PODERES RELIGIOSOS}

Para concluir, ou seja, para relançar, é difícil não estar de acordo com as considerações finais do comentário de Pace. A atualidade obriga-nos a refletir bem se é o caso de desistir da separação entre poderes políticos e poderes religiosos, ou, pelo contrário, se não seja o caso de lutar ainda mais vigorosamente por ela.

Todavia, também e sobretudo quando se responde desta última forma ("é preciso lutar pela separação entre poderes políticos e poderes religiosos"), como pessoalmente julgo oportuno, torna-se urgente se perguntar: para qual tipo de separação entre poderes políticos e poderes religiosos deve-se lutar? Pela laicidade ou pela liberdade religiosa?

Também admitindo que os modelos modernos de separação sejam apenas dois (laicidade e liberdade religiosa) e, mais ainda, que fossem mais numerosos, deve ser rejeitada com força, a partir de uma sede puramente analítica, a pretensão característica da laicidade de confundir laicidade

Debates do NER, Porto Alegre, ano I6, N. 27, P. I27-I4I, JAN./Jun. 2015 
e separação. Aqui, como em toda a confusão estudada, esconde-se - na forma de abuso cognitivo e da ideologia - não o germe, mas a planta já robusta da violência.

Em suma, frente ao fogo dos terroristas existem muitas razões para dizer "je suis Charlie", e para fazê-lo, sem mas ou poréns. Quando, no entanto, se passa à fase costruens, é possível que seja "je ne suis pas Charlie" o que se deva dizer. E, de resto, não são poucos os que avançaram a suspeita de que a laicidade não é outra coisa a não ser império e violência de uma outra e mais ambígua religião, a religião do político que se fez absoluta na forma de "Estado" e que se tornou invisível atrás do véu de uma suposta razão imposta como única.

\section{REFERÊNCIAS}

CASANOVA, José. Oltre la secolarizzazione. Bologna: Il Mulino, 2000.

The Secular in Secularism. Social Research, v. 4, New York, p. 1049$-1066,2009$.

DIOTALLEVI, Luca. L'ordine imperfetto: Modernizzazione, Stato, secolarizzazione. Soveria Mannelli, CZ: Rubbettino, 2014.

GORSKI, Philip. Historicizing the secularization debate: Church, State, and Society in late Medieval and Early Modern Europe, ca. 1300 to 1700. American Sociological Review, n. 65, p. 138-167, 2000.

The Secular, Secularizations, Secularisms. In: CALHOUN, Craig; JUERGENSMEYER, Mark; VAN ANTWERPEN, Jonathan. Rethinking Secularism. Oxford: Oxford University Press, 2011. p. 54-74.

LUHMANN, Niklas. Funktion der Religion. Frankfurt: Suhrkamp, 1977. La differenziazione del diritto. Bologna: Il Mulino, 1990. Das recht der gesellschaft. Frankfurt: Suhrkamp, 1995. 
. Die Gesellchaft der Gesellchaft. v. 2. Frankfurt: Suhrkamp, 1997. I diritti fondamentali come istituzione. Bari: Dedalo, 2002. . Organizzazione e decisione. Milano: Bruno Mondadori, 2005.

SIMMEL, Georg. La differenziazione sociale. Roma; Bari: Laterza, 1982.

TURNER, Bryan. Religion and Modern Society: Citizenship, Secularization and the State. Cambridge, UK: Cambridge University Press, 2011.

Recebido em: 04/02/2015

Aprovado em: 10/02/2015

Debates do NER, Porto Alegre, ano I6, N. 27, P. I27-I4I, Jan./Jun. 2015 